\title{
Green Processing of Strategic Elements Based on Magnetic Nanohydrometallurgy
}

\author{
Ulisses Condomitti, Sabrina N. Almeida, Alceu T. Silveira Jr., Fernando M. de Melo and \\ Henrique E. Toma*
}

\author{
Instituto de Química, Universidade de São Paulo, 05508-000 São Paulo-SP, Brazil
}

\begin{abstract}
Magnetic nanohydrometallurgy (NHM) is a new process based on engineered superparamagnetic nanoparticles capable of performing as complexing agents for extracting and recovering strategic metals from mineral sources and urban wastes, as well as for removing hazardous elements from contaminated water. Its principles and application are reviewed in this paper. Typical examples involving copper, silver and mercury processing are here discussed, including the exploitation of a novel nanotechnological strategy for capturing and fractionating rare earth elements.
\end{abstract}

Keywords: magnetic nanohydrometallurgy, strategic elements, lanthanides, elemental sustainability, green chemistry

\section{Introduction}

Elemental sustainability is an important topic in modern science and technology, ${ }^{1,2}$ deserving special attention regarding the rational use and exploitation of the global mineral resources. ${ }^{3}$ Today, the concerns about the natural resources, specially biomass, oil, coal and water are being extended to strategic elements, including copper, noble metals and lanthanides, since they are being depleted, and their availability is impacting the economy, social welfare and sustainability.

In Brazil, mineral exploration has a large contribution to the gross national product, but like in many other countries, the activity has been a source of environmental problems. ${ }^{4}$ Most of the technologies are being directed to the extraction of commercial ores for exportation as commodities. The biggest challenge for developing countries like Brazil is to surpass their present status of commodity producers, by investing in high technology capable of supplying the strategic elements required by the modern technology.

Extractive metallurgy has been performed all over the world to obtain the elements from their ores, and comprises two main routes: pyrometallurgy and hydrometallurgy..$^{5-8} \mathrm{As}$ an ancient process, pyrometallurgy involves the reduction of the metal ores with carbon or sacrificial elements, such as aluminum, in large furnaces. The process demands rich metal ores and high energy consumption, generating large

*e-mail: henetoma@iq.usp.br

This paper is part of the PubliSBQ Special Issue "IUPAC-2017" (http://publi.sbq.org.br/). amounts of scoria while releasing huge quantities of carbon dioxide into the atmosphere. For this reason, the process is being criticized for its poor Green Chemistry performance. ${ }^{5}$

Hydrometallurgy, on the other hand, is considered a relatively greener alternative. It starts from the treatment of the metal ores with acids, alkali or bacteria, ${ }^{9}$ in order to release the metal ions. In this way, it is possible to exploit metal oxide and carbonate ores which usually exhibit a low metal content, instead of the rich sulfide ores employed in pyrometallurgy. Metal sulfide ores can also be employed in hydrometallurgy, but only after a suitable chemical or biological treatment. ${ }^{10-13}$ In conventional hydrometallurgy, the aqueous effluents containing the metal ions are collected in huge reservoirs and treated with complexing agents such as organic oximes, in order to capture the dissolved metal ions. Then, metal-organic complexes are extracted by solvents such as tributylphosphate, di-2-ethylhexylphosphate and kerosene. ${ }^{14}$ After releasing the metal ions using acidbase treatment, their electrowinning is conducted in large electrochemical cells, where the pure elements are deposited, by electrolysis, onto suitable metal cathodes. ${ }^{14}$

Hydrometallurgy has been successfully applied to the production of strategic elements such as aluminum, cobalt, copper, gold, molybdenum, nickel, platinum, selenium, silver, tellurium, tungsten, uranium, zirconium and rare earths. ${ }^{15}$ It leads to high purity metals in contrast with pyrometallurgy, and can be conducted at room temperature, encompassing a rational engineering design which allows the recovery of most of the chemical reagents and solvents. ${ }^{16-25}$ However, hydrometallurgy cannot be performed without 
using huge amounts of organic solvents and intensive chemical processing in the complexation and extraction steps, as well as in the metal release with acid treatment, also employed for recycling of the complexing agents.

Nowadays, the accumulation of electronic wastes is becoming another point of environmental concern, already impacting the urban life. It should be noticed that electronic products contain expressive amounts of valuable elements, as exemplified by copper, silver, gold and paladium. ${ }^{26,27}$ This fact is leading to urban mining; a real enterprise for recycling the precious elements, cleaning the environment and preventing negative consequences of the mineral exploration, sometimes of catastrophic proportions. Urban mining is already very important in the recycling of elements such aluminum, iron, copper and zinc. Very soon, lanthanides from commercial magnets and catalysts will also be found in high amounts in industrial urban wastes. Lithium, from the electronic batteries, is another important candidate.

In contrast with the classical pyrometallurgical and hydrometallurgical processes, urban mining can be conducted in small scale, and is open to new investments, novel technologies and ideas. In this regard, this review article will focus on a new, emerging technology called magnetic nanohydrometallurgy, or simply NHM..$^{28}$ The process was developed in our laboratory ${ }^{29}$ and is based on the use of superparamagnetic nanoparticles functionalized with complexing agents, for extracting, concentrating and separating the metal elements, under the influence of applied magnetic field, and in some cases, to perform the electrowinning process after magnetically confining the metal ions onto the appropriate cathode surface.

NHM has been successfully applied to the extraction and recovery of metals such as $\mathrm{Cu}, \mathrm{Hg}$ and $\mathrm{Ag}$ ions, as we recently reported in the literature. ${ }^{28,30-33}$ As an extension, we here report on our recent advances, extending the NHM technology to a challenging area of the rare earth (RE) elements, particularly the lanthanides. This group of elements is normally found in the trivalent state, and is very important in modern technology because of their applications in catalysis, ${ }^{34}$ metallurgy, ceramics, medicine, ${ }^{35-38}$ electronics and energy. ${ }^{39,40}$ The major lanthanide ores consist of monazite, bastnäsite and xenotime. ${ }^{41}$ Monazite is a phosphate mineral of thorium and light rare earth elements such as $\mathrm{Ce}$ (45\%), $\mathrm{La}(23 \%)$ and $\mathrm{Nd}(17 \%)$. These elements are actually most relevant, comprising about $95 \% \mathrm{RE}$ consumption in the industries. Minor amounts of $\mathrm{Pr}, \mathrm{Sm}, \mathrm{Gd}$ and $\mathrm{Y}$ are also present in monazite. Bastnäsite, a fluorocarbonate mineral, is another important source of light rare earths, while xenotime, is a phosphate mineral containing mainly heavy rare earth elements.
Brazil and India were the first lanthanide producers about five decades ago. Nowadays, the production is dominated by China, which also possesses one of the largest reserve $(25 \%)$ of the RE elements in the world..$^{42}$ However, recent discoveries in Brazil are ranking the country in a leading position among the many countries. ${ }^{40}$ But Brazilian production remains yet quite modest or insignificant up to the present time. Although a Brazilian Initiative in Rare Earths Technology has been launched by the government in $2013,{ }^{43}$ the unfavorable economic situation has, unfortunately, severely limited the progress in this area.

Extraction of neodymium from monazite is particularly of great relevance, because of its application in commercial supermagnets, such as those based on $\mathrm{Nd}_{2} \mathrm{Fe}_{14} \mathrm{~B}$ alloys. ${ }^{40}$ In mineral processing, after the removal of thorium phosphate and insoluble $\mathrm{CeO}_{2}$ products from monazite, a concentrate is obtained containing mainly $\mathrm{La}^{3+}$ and $\mathrm{Nd}^{3+}$ ions, with smaller amounts of the other elements. Such concentrates are usually processed by rather elaborate solvent extraction methods and ionic exchange. ${ }^{44-50}$ However, it should be mentioned that lanthanide ions separation is far from trivial, since the elements exhibit very similar chemical properties, and the only possibility of success relies on the exploitation of the so called lanthanide contraction accompanying the increase of the atomic number. Such radial contraction determines the relative trends of the stability constants of the complexes, allowing some discrimination between the elements, which can be employed for separation purposes.

\section{High Performance Superparamagnetic Nanoparticles}

For industrial purposes, the capture and processing of strategic metal elements using the NHM process require very efficient superparamagnetic nanoparticles, exhibiting, for instance:

(i) strong magnetic cores displaying little or no hysteresis at room temperature;

(ii) great stability in aqueous solution under normal conditions, e.g., in the presence of oxygen (air), high stirring rates and variable $\mathrm{pH}$;

(iii) large surface area and great mobility in solution;

(iv) a protecting coating for preserving the magnetic core from the chemical environment;

(v) an additional functional coating encompassing effective complexing agents;

(vi) a large concentration of the complexing agents at the surface;

(vii) a good chemical reversibility for exchanging complexed metal ions with protons in the processing steps; 
(viii) high magnetic recovery rates for effective recycling;

(ix) low toxicity, offering minor risks for the environment;

$(x)$ low cost, allowing production in large scale.

In order to achieve such goals, an elaborate nanoparticles design is necessary. First, high quality magnetic nanoparticles are required to form the cores, and their magnetization profile should be monitored, e.g., by using vibrating magnetometers or superconducting quantum interference device (SQUID) equipment. A convenient nanomaterial for most purposes is magnetite, $\mathrm{Fe}_{3} \mathrm{O}_{4}$, because of its large magnetization response in a magnetic field, and relatively simple preparation. Magnetite is a black solid exhibiting an inverted spinel structure of the type $\mathrm{Fe}^{\mathrm{II}} \mathrm{Fe}^{\mathrm{III}}{ }_{2} \mathrm{O}_{4}$, where the iron(II) ions occupy octahedral sites and the iron(III) ions are equally distributed in octahedral and tetrahedral sites. ${ }^{51}$ Because of the geometrical disposition, the iron(III) ions are antiferromagnetically coupled, so that only the iron(II) ions contribute for the net magnetization behavior of magnetite. In the nanocrystalline form (Figure 1) its saturation magnetization is usually found in the range of 90-98 emu $\mathrm{g}^{-1}$ at room temperature. ${ }^{51}$ Another useful magnetic material is maghemite, or $\gamma-\mathrm{Fe}_{2} \mathrm{O}_{3}$, which is composed exclusively by iron(III) ions. It is a brown solid, usually obtained by the air oxidation of magnetite, exhibiting a slightly smaller saturation magnetization, e.g., 76- $81 \mathrm{emu} \mathrm{g}^{-1}$, but a greater stability in air, in relation to magnetite.

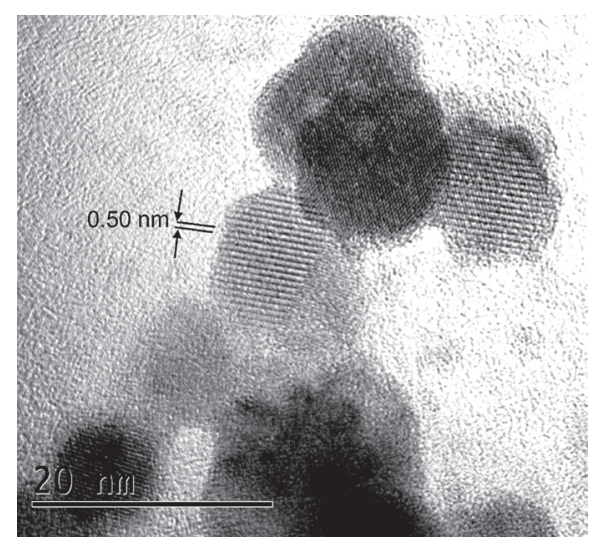

Figure 1. High resolution transmission electron microscopy (HR-TEM) image of magnetite nanoparticles showing the internal crystalline structure, with the characteristic interplanar distances.

Hysteresis is another important aspect to be considered in the magnetic behavior, and is responsible for the memory effect observed in large, multidomain particles. Its absence is characteristic of the superparamagnetic behavior exhibited by typical nanoparticles. Thanks to this property, the nanoparticles stay randomly dispersed, exhibiting little mutual interaction in the absence of a magnetic field.
However, by applying a magnetic field, the nanoparticles are strongly attracted to the poles, as a consequence of the induced magnetization response.

The nanoparticles stability in solution can be described by the theory proposed by Derjaguin, Landau, Vervey and Overbeek, ${ }^{52,53}$ also known as DLVO, encompassing the electrostatic repulsion from the surface charges, and the steric repulsion from the adsorbed molecular chains. The electrostatic repulsion increases with the presence of ionized groups at the surface, such as the negatively charged carboxylate ligands. The metal ions captured can also impart a net positive charge to the particles, promoting their stabilization. On the other hand, the ligands at the surface can also be protonated, decreasing the net negative charge, and competing with the binding of the metal ions.

For long term use, the coating of the nanoparticles core with a protecting shell, e.g., of silica (Figure 2), is particularly important, in order to prevent the leaching of the exposed surface ions and preclude their interference in the measurements, particularly in the presence of complexing agents, including buffer ions such as phosphate and acetate. The coating also offers protection against air oxidation which gradually converts magnetite into maghemite, provoking some decay in the magnetization properties. The protecting shell should also provide a suitable surface for anchoring the complexing agents. In the case of silica, the coating is usually performed by applying organosilanes, such as $\mathrm{Si}\left(\mathrm{OC}_{2} \mathrm{H}_{5}\right)_{4}$, by means of their controlled hydrolysis as in the Stöbber method. ${ }^{54}$ The silica coating is suitable for further treatment with functionalized organosilanes, such as amino-, mercaptoor carboxy- propylsilane, $\mathrm{Si}\left(\mathrm{OC}_{2} \mathrm{H}_{5}\right)_{3}\left(\mathrm{C}_{3} \mathrm{H}_{6}\right) \mathrm{R}\left(\mathrm{R}=-\mathrm{NH}_{2}\right.$, $-\mathrm{SH},-\mathrm{COOH}$ ), namely aminopropylsilane (APTS), mercaptopropylsilane (MPS) and carboxipropylsilane (CPS). For a short term use, a molecular coating can be directly applied to the magnetic core, e.g., with oleic or stearic acid, or soluble polymers. The use of fatty acids is particularly interesting for adsorbing the particles in carbon materials, providing a new class of magnetic carbon for adsorption purposes. Carbon materials, such as carbon black, graphite, glassy carbon and pyrolitic carbon provide low cost and relatively inert electrodes, ${ }^{55,56}$ with large surface areas for adsorption and separation processes, particularly in industry and water treatment. ${ }^{57,58}$

\section{Magnetic Nanohydrometallurgy Applied to Lanthanide Elements}

In the case of lanthanide separation, a suitable nanoparticle has been obtained by attaching a strongly complexing agent such as ethylenediaminetetraacetic (EDTA) or diethylenediaminepentaacetic acids (DTPA), 


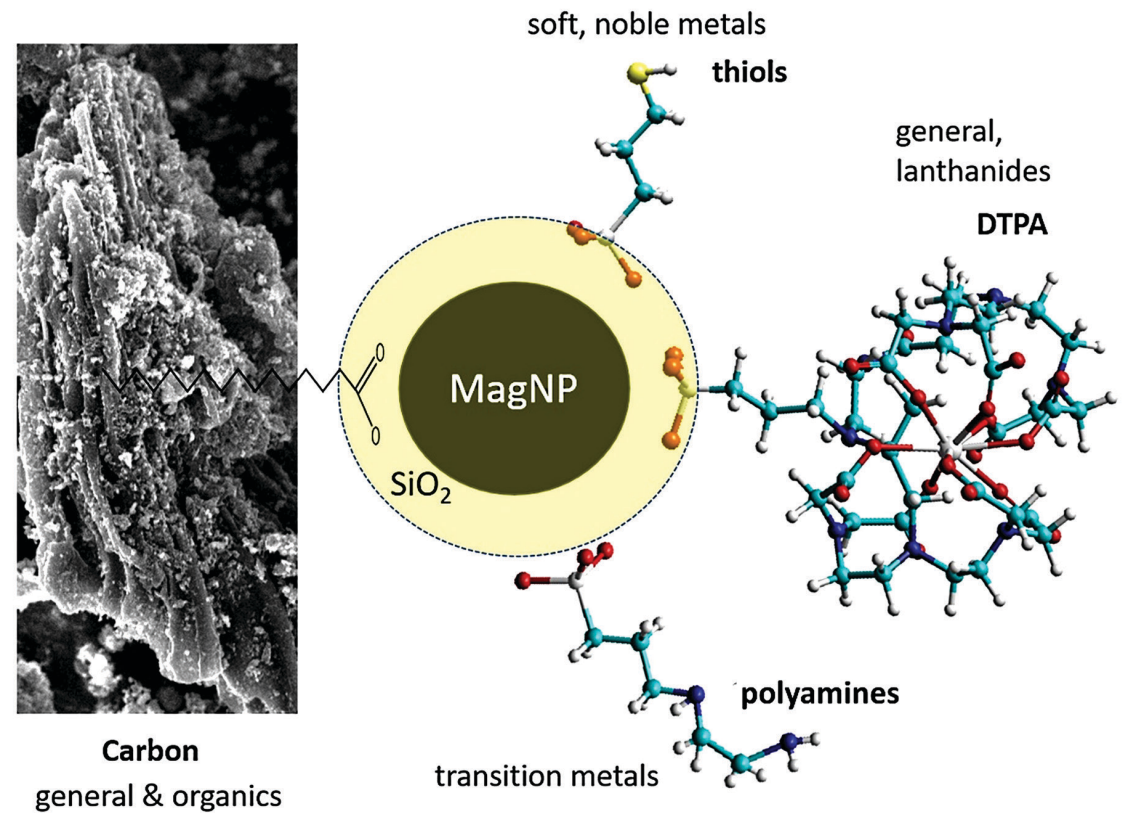

Figure 2. Typical functionalized superparamagnetic nanoparticles for NHM applications, encompassing activated carbon (for general applications), thiols and amines (for transition metal ions), and diethylenetriaminepentaacetic acid (DTPA) (for representative, lanthanide and transition metals).

using ethylenediaminepropyltriethoxysilane (EAPS) as the anchoring group (Figure 1). $\mathrm{Fe}_{3} \mathrm{O}_{4} @ \mathrm{SiO}_{2}$ (EAPS) nanoparticles exhibiting an average solvodynamic radius of $20 \mathrm{~nm}$ have been employed for anchoring of the DTPA agents. The process involves the direct reaction of the amine groups with DTPA anhydride, and leads to stabilized nanoparticles of average solvodynamic radius around $25 \mathrm{~nm}$. As shown in Figure 3, the starting $\mathrm{Fe}_{3} \mathrm{O}_{4} @ \mathrm{SiO}_{2}$ (EAPS) nanoparticles exhibit a positive charge in aqueous solution, below $\mathrm{pH} 8$, due to the protonation of the amino groups. After the binding of DTPA, the charges are exchanged above $\mathrm{pH} 5$, due to the ionized carboxylate groups. In general, zeta potentials above $\pm 30 \mathrm{mV}$ can keep the charged nanoparticles suspended in solution, preventing their agglomeration by means of the electrostatic repulsion.

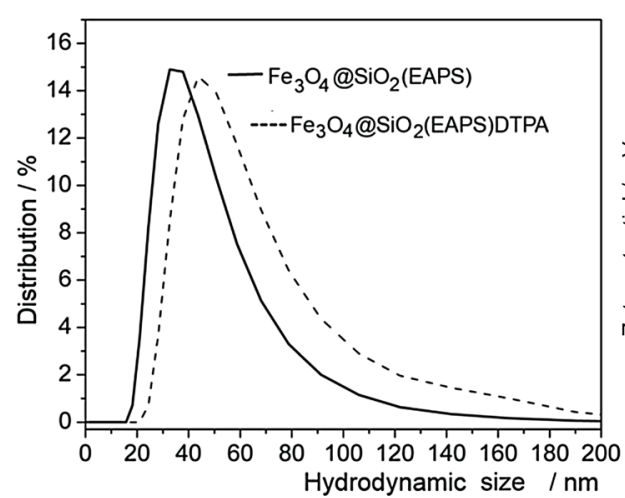

For the sake of clarity, the $\mathrm{Fe}_{3} \mathrm{O}_{4} @ \mathrm{SiO}_{2}$ (EAPS)DTPA nanoparticles will be simply expressed as NP@DTPA. The functionalized nanoparticles have been employed in the capture of lanthanide ions, and a selection of the $\mathrm{La}^{3+}\left(5 f^{\circ}\right), \mathrm{Nd}^{3+}\left(5 f^{3}\right)$ and $\mathrm{Dy}^{3+}\left(5 f^{8}\right)$ ions will be specially focused because of their contrasting magnetic behavior and relatively distinct ionic radii. It has been shown ${ }^{59}$ that the capture of the lanthanide ions $\left(\mathrm{Ln}^{3+}\right)$ by NP@DTPA proceeds according to the equilibrium:

$\mathrm{NP} @ \mathrm{DTPA}+\mathrm{Ln}^{3+} \rightleftharpoons \mathrm{NP} @ \mathrm{DTPA}-\mathrm{Ln}$

expressed by:

$$
\mathrm{K}=\frac{[\mathrm{NP} @ \mathrm{DTPA}-\mathrm{Ln}]}{[\mathrm{NP} @ \mathrm{DTPA}]\left[\mathrm{Ln}^{3+}\right]}
$$

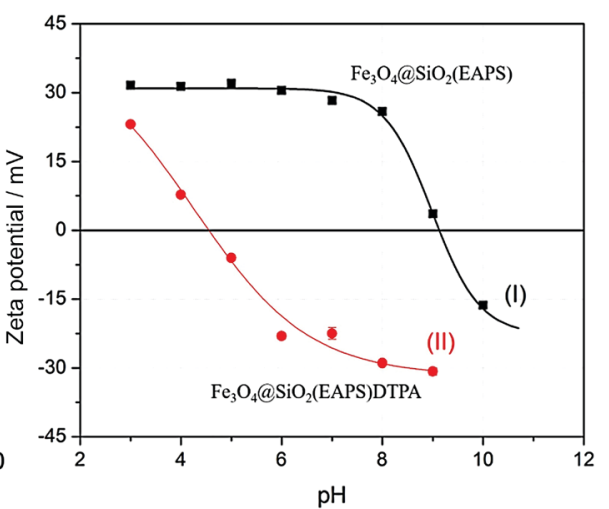

Figure 3. Solvodynamic radius distribution of $\mathrm{Fe}_{3} \mathrm{O}_{4} @ \mathrm{SiO}_{2}(\mathrm{EAPS})$ and $\mathrm{Fe}_{3} \mathrm{O}_{4} @ \mathrm{SiO}_{2}(\mathrm{EAPS}) \mathrm{DTPA}$ nanoparticles in aqueous solution (left), and their corresponding zeta potentials as a function of $\mathrm{pH}$ (right). 
It should be noted that in the Langmuir approach, the binding or adsorption process involves equivalent sites distributed at the nanoparticles surface, forming just a single monolayer of adsorbates. However, in the systems reported here, the reaction was found to proceed very slowly, requiring a constant stirring and a long time for achieving equilibrium. A typical reaction time of $300 \mathrm{~min}$ has been employed in the experiments, in order to ensure completeness. From this observation, it is plausible that the binding of the metal ions to complexing agents such as DTPA involves a large number of competing groups in the binding sites, leading to several intermediate coordination and conformational structures at the nanoparticles surface. Such species, in dynamic equilibrium, would demand a long time to convert to the final stable species.

Calling $\theta$ the fraction of adsorption sites occupied by the $\mathrm{Ln}^{3+}$ ions, the corresponding fraction of unattached sites is $(1-\theta)$. Therefore,

$\frac{\mathrm{NP} @ \mathrm{DTPA}-\mathrm{Ln}}{[\mathrm{NP} @ \mathrm{DTPA}]}=\frac{\theta}{(1-\theta)}$

At equilibrium, the concentration of the lanthanide ions, $\left[\mathrm{Ln}^{3+}\right]$, can be taken as $\mathrm{C}_{\mathrm{eq}}$, and the equilibrium constant becomes:

$\mathrm{K}=\frac{\theta}{\mathrm{C}_{\mathrm{eq}}(1-\theta)}$

or,

$\theta=\frac{\mathrm{KC}_{\mathrm{eq}}}{1+\mathrm{KC}_{\mathrm{eq}}}$

The adsorbed amount of lanthanide ions at equilibrium concentration is equal the difference of the initial and equilibrium $\mathrm{Ln}^{3+}$ concentrations, $\mathrm{C}_{\mathrm{o}}$ and $\mathrm{C}_{\text {eq }}$, respectively. One can define $\mathrm{q}_{\mathrm{eq}}$ as the adsorbed amount lanthanide ions at equilibrium concentration per adsorbent mass (m), magnetic nanoparticles (MagNP), in a given volume $\mathrm{V}$,

$\mathrm{q}_{\mathrm{eq}}=\frac{\left(\mathrm{C}_{0}-\mathrm{C}_{\mathrm{eq}}\right) \mathrm{V}}{\mathrm{m}}$

Since

$\theta=\frac{\mathrm{q}_{\mathrm{eq}}}{\mathrm{q}_{\max }}$

it follows

$$
\mathrm{q}_{\mathrm{eq}}=\frac{\mathrm{KC}_{\mathrm{eq}} \mathrm{q}_{\text {max }}}{\left(1+\mathrm{KC}_{\mathrm{eq}}\right)}
$$

The plot of $\mathrm{q}_{\mathrm{eq}}$ versus $\mathrm{C}_{\mathrm{eq}}$ allows to trace the Langmuir isotherm, and normally exhibits a characteristic curvature, approaching a saturation point at higher concentrations of the lanthanides, corresponding to $\mathrm{q}_{\max }$. The corresponding plot for $\mathrm{La}^{3+}$ ions can be seen in Figure 4 .

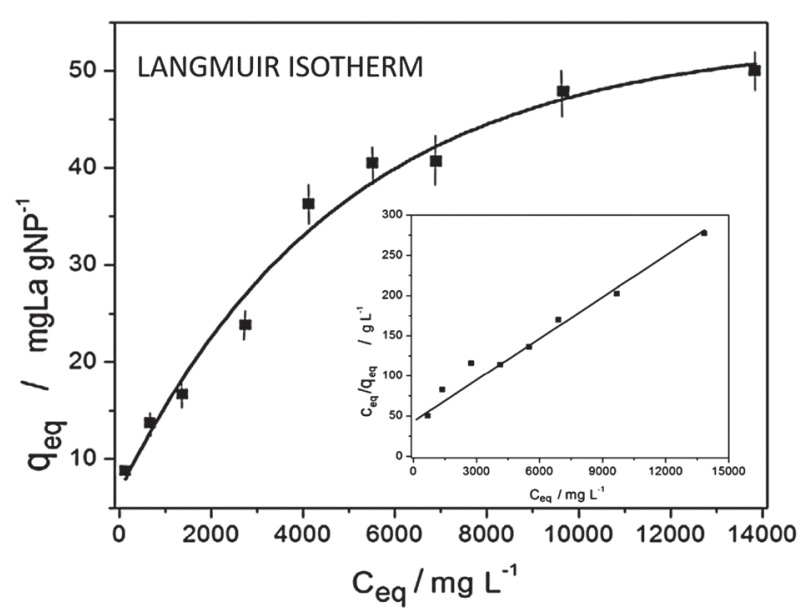

Figure 4. Adsorption isotherm of NP@DTPA in $\mathrm{La}^{3+}$ solutions at $298 \mathrm{~K}$. Inset, linear plot of the Langmuir adsorption isotherm (reproduced with permission from reference 59).

It is also convenient to express equation 8 in the linearized form:

$\frac{\mathrm{C}_{\mathrm{eq}}}{\mathrm{q}_{\mathrm{eq}}}=\frac{1}{\mathrm{q}_{\max } \mathrm{K}}+\frac{\mathrm{C}_{\mathrm{eq}}}{\mathrm{q}_{\max }}$

and the corresponding plot is shown in Figure 4 (inset).

From the slope and intercept of the linear plot, the maximum amount of attached $\mathrm{La}^{3+}$ ions $\left(\mathrm{q}_{\max }\right)$ and their corresponding equilibrium constant, $\mathrm{K}$, can be evaluated.

There are several other methodologies for analyzing the adsorption of species at the nanoparticles surface, such as the Freundlich treatment, ${ }^{60}$ which is particularly suitable for multilayered adsorption and more complex processes. We preferred the Langmuir isotherm, because it preserves the analogy with the conventional equilibrium processes occurring in homogeneous systems, and seems particularly appropriate for describing the capture of metal ions by the complexing nanoparticles. Although it is also possible to express the equilibrium in terms of mol instead of mass, the lack of an acceptable molecular weight for the MagNPs turns such option less adequate. Nanoparticles can exhibit different shapes and sizes, and any attempt to evaluate the number of active sites would be rather speculative. For this 
reason, the Langmuir isotherms are usually expressed in terms of the mass of adsorbates to the mass of nanoparticles.

Typical equilibrium constants reported for $\mathrm{La}^{3+}$, $\mathrm{Nd}^{3+}$ and $\mathrm{Dy}^{3+}$ ions were $2.92 \times 10^{-4}, 4.22 \times 10^{-4}$ and $2.57 \times 10^{-3} \mathrm{~g}(\mathrm{MagNP}) \mathrm{L}^{-1}$, respectively. ${ }^{59,61}$ This data reflects the normal trends in the stability constants for the lanthanide DTPA and related complexes, ${ }^{62}$ guided by the lanthanide contraction along the series. The maximum amount of captured $\mathrm{Ln}^{3+}$ ions were typically $60 \mathrm{mg}\left(\mathrm{Ln}^{3+}\right)$ per $\mathrm{g}(\mathrm{MagNP})$, or $6 \% \mathrm{~m} / \mathrm{m}$.

\section{Magnetophoretic Study of the Capture of Lanthanide lons by NP@DTPA}

The metal capture by the DTPA functionalized superparamagnetic nanoparticles was found to proceed according to a slow kinetics in aqueous solution, and can be monitored by taking samples at different times and analyzing the elemental composition using conventional spectrophotometric or X-ray fluorescence techniques. The analytical procedures require the magnetic separation of the nanoparticles from the solution, and the overall study becomes cumbersome because of the many repetitive assays and validation tests, depending on the experimental variables associated with the samples (time, mass, volume, stirring, nanoparticles size) and the instrumental setup.

It should be noted that the capture of metal ions can change the solvodynamic radii and magnetization of the superparamagnetic nanoparticles, and in this way, it can have some influence on their migration rates in the presence of an applied magnetic field..$^{63}$ The subject is related to magnetophoresis, an emerging area of investigation, aiming the use of superparamagnetic nanoparticles in separation processes, by analogy to electrophoresis. However, magnetophoresis is not completely understood yet, and has been the subject of many recent studies, ${ }^{64-68}$ particularly focusing on theoretical aspects.

Because of their small size, the magnetic nanoparticles can follow complex pathways directed by the applied magnetic fields, being perturbed by the non-homogeneous field distribution and by the influence of the thermal energy and the counteracting viscous drag forces. ${ }^{69}$ The high complexity of the analytical solutions dealing with inhomogeneous magnetic fields, imposes a big challenge in the theoretical treatment of magnetophoresis.

In the simplest theoretical approach, ${ }^{70}$ isolated nanoparticles of radius $\mathrm{R}$ and magnetic moment $\mathrm{m}$ exposed to the magnetic field gradient of an applied field $\mathrm{H}$, are attracted by a force $\left(\mathrm{F}_{\mathrm{mag}}\right)$ expressed by:

$$
\mathrm{F}_{\text {mag }}=\mathrm{m}(\mathrm{H}) \mu_{0}\left[\frac{\partial \mathrm{H}}{\partial \mathrm{r}}\right]
$$

where $\mu_{0}$ is the magnetic constant (equal 1 in cgs unit).

In most typical situations, the magnetic particles are relatively distant from the magnet and the gradients are smaller than $100 \mathrm{~T} \mathrm{~m}^{-1}$, corresponding to a low field magnetophoretic regime. ${ }^{66,71}$ In this case, the moment is proportional to $\mathrm{H},(\mathrm{m}=\chi \mathrm{H})$, and equation 10 becomes:

$\mathrm{F}_{\mathrm{mag}}=\chi \mu_{0} \mathrm{H}\left[\frac{\partial \mathrm{H}}{\partial \mathrm{r}}\right]$

The displacement of the magnetic nanoparticles should oppose the viscous drag force $\left(\mathrm{F}_{\mathrm{vis}}\right)$ exerted by the solvent,

$$
\mathrm{F}_{\mathrm{vis}}=6 \pi \eta \mathrm{R} v
$$

where $\eta$ is the viscosity, and $v=$ velocity. From the balance of such forces, one can extract the magnetophoretic velocity $\mathrm{v}$,

$v=\frac{1}{6 \pi \eta \mathrm{R}} \chi \mu_{0} \mathrm{H}\left[\frac{\partial \mathrm{H}}{\partial \mathrm{r}}\right]$

Therefore, the migration of the isolated nanoparticles of magnetic moment $\chi \mathrm{H}$ is proportional to the magnetic field $\mathrm{H}$ and to the magnetic field gradient $(\partial \mathrm{H} / \partial \mathrm{r})$, and inversely proportional to the solvent viscosity and the solvodynamic radius.

In the high field limit, such as when the particles are very close to the magnet, the magnetic moment (m) approaches saturation, becoming almost insensitive to changes in the field. In this case, its contribution to the measurements is practically negligible, since the nanoparticles would be practically at the end point of their trajectory.

There are many different experimental designs for monitoring magnetophoresis. We have already proposed a rather simple and didactic approach, based on external weighing in the presence of a magnetic field, using an analytical balance, ${ }^{61,63}$ and a versatile LEGO $^{\circledR}$ toy setup. The typical arrangement involved a non magnetic assembly positioned on the balance plate, using a diamagnetic cantilever (nuclear magnetic resonance, NMR, or electron paramagnetic resonance, EPR, tube) to support the sample tube, as shown in Figure 5. A small neodymium magnet $\left(\mathrm{Nd}_{2} \mathrm{Fe}_{14} \mathrm{~B}\right)$ can be employed, but it should be precisely positioned at the bottom of the sample tube arrangement. It is important to note that, because of the large magnetization of the $\mathrm{Fe}_{3} \mathrm{O}_{4}$ nanoparticles (typically $92 \mathrm{emu} \mathrm{g}^{-1}$ ), the weight increase measured in the analytical balance can be hundred times higher than the original weight of the nanoparticles. For this reason, a counterpoise is required to equilibrate the balance plate arrangement. 


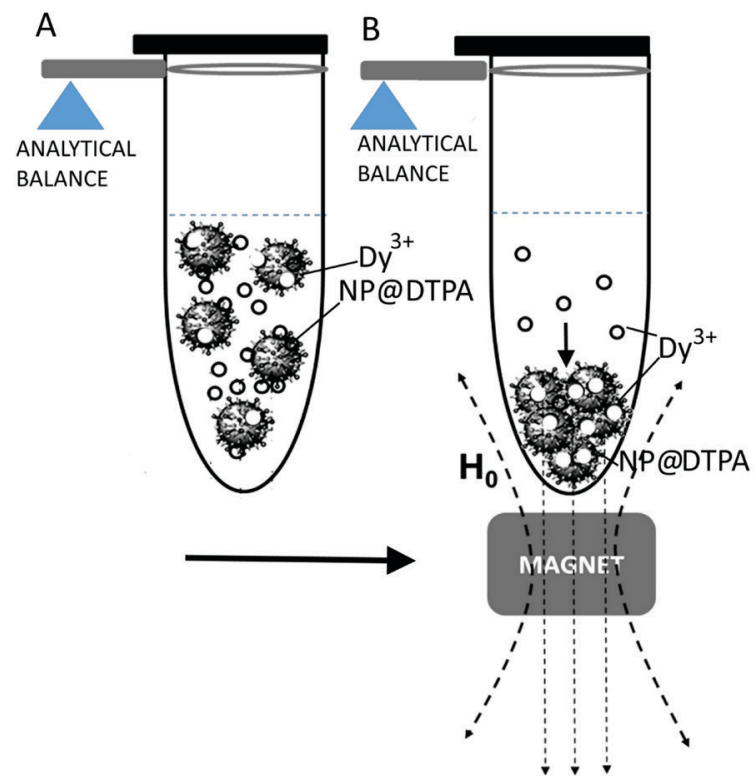

Figure 5. Capture of $\mathrm{Dy}^{3+}$ ions by NP@DTPA monitored by the magnetophoretical rates using an analytical balance. ${ }^{63}$

The mentioned device has proved versatile and adequate for probing the magnetophoretic migration in fluids, by measuring the relative weight increase accompanying the attraction of the particles by the magnet as long as they move to the bottom. The contribution of gravity and of the magnetic attraction on the paramagnetic ions in solution is completely negligible in relation to the relative weight increase observed experimentally. In this way, by monitoring the weight as a function of time one can obtain the magnetophoretic deposition rates, from which it is possible to evaluate the corresponding kinetics, and determine the velocity constants. The observed response actually reflects an average profile, because of the convective fluid motion induced by the different magnetophoretic velocities at the top and bottom of the system. ${ }^{64}$ By changing the distance from the magnet, the kinetics and the relative weight at the equilibration point are strongly affected by the magnetic field as predicted by equation 13 , the magnetophoretic rates decrease at longer distances from the magnet. ${ }^{61}$

Magnetophoresis has been successfully applied ${ }^{61}$ to the capture of Dy ${ }^{3+}$ ions by the NP@DTPA nanoparticles (Figure 5).

$$
\text { MagNP@DTPA + Dy }{ }^{3+} \rightleftharpoons \text { MagNP@DTPA-Dy }
$$

It should be noted that although the $\mathrm{Dy}^{3+}$ solution $\left(0.1 \mathrm{~mol} \mathrm{~L}^{-1}\right)$ exhibits a typical paramagnetic behavior, under normal conditions, its contribution to the weight increase during the magnetophoresis experiments is completely negligible, in relation to magnetic response of the nanoparticles. In this way, after the addition of NP@DTPA to the $\mathrm{Dy}^{3+}$ solution, the magnetophoretic response results similar to that observed in pure water, indicating that the capture of the metal ions proceeds rather slowly. In order to monitor the kinetics, the mixture was kept under constant stirring in a microtube, and after a time interval, e.g., of $25 \mathrm{~min}$ the sample was submitted to magnetophoresis monitored by the analytical balance. Instead of the expected weight increase due to the capture of the $\mathrm{Dy}^{3+}$ ions, the opposite result has been observed, and proceeded up to the equilibrium point after $300 \mathrm{~min}$ as illustrated in Figure 6.

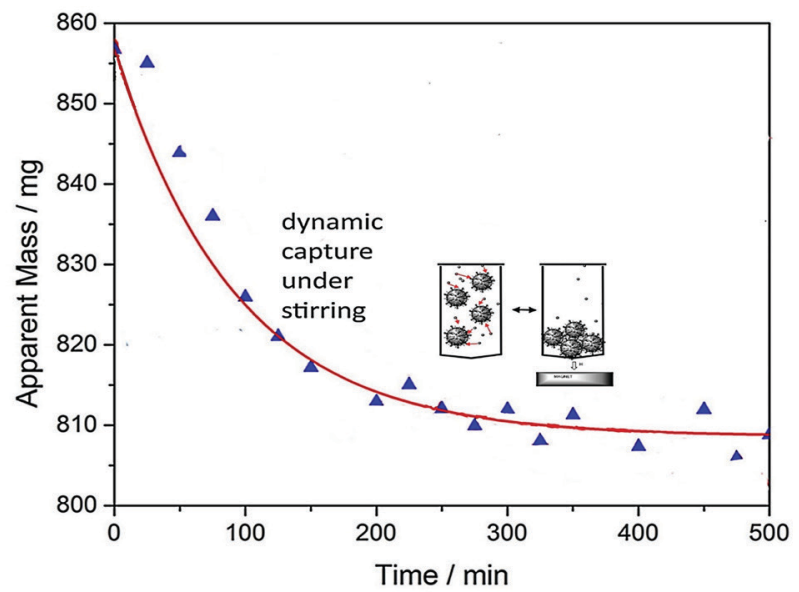

Figure 6. Magnetophoretic response of the MagNP@DTPA-Dy system (adapted, with permission, from references 61 and 63).

After the binding of the Dy ${ }^{3+}$ ions, the decrease of magnetism corresponded to $5.9 \%$ of the initial magnetization value. This result indicated that the paramagnetic $\mathrm{Dy}^{3+}$ ions decrease the overall magnetism of the nanoparticles, implying in a dipolar anti-ferromagnetic coupling between the lanthanide and magnetic core spins. The magnetophoretic velocity also slightly decreased after the binding of $\mathrm{Dy}^{3+}$ ions, consistent with the decrease of the magnetization of the nanoparticles and with the increase of the hydrodynamic radii due to the presence of the captured metal ions.

Scanning transmission electronic microscopy (STEM) equipped with a high-angle annular dark field (HAADF) detection and energy dispersive X-ray spectroscopy (EDX) analysis has allowed to probe the element distribution around the MagNP@DTPA-Dy particles, as illustrated in Figure 7, where the elements are discriminated by their corresponding colors, e.g., Dy (red), Fe (blue), C (yellow) and Si (green) at the surface. ${ }^{61} \mathrm{An}$ important observation is that the red spots representing the dysprosium ions are located over the yellow stain, comprising the DTPA ligand, as expected from the capture of the lanthanide ion by the complexing agent.

Considering the nucleus magnetic core, one can see that the $\mathrm{Dy}^{3+}$ ions are located in a region of negative field 

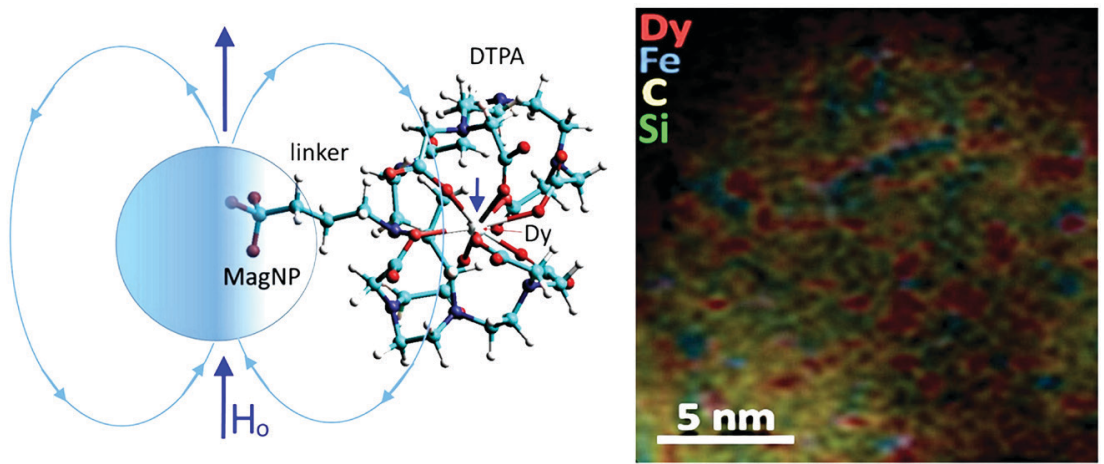

Figure 7. (left) Pictorial representation of the interaction between MagNP@DTPA and dysprosium ions, indicating an antiferromagnetic coupling; (right) HAADF image of a MagNP@DTPA-Dy nanoparticle showing the elemental map distribution obtained by EDX, represented by corresponding colors.

gradients, thus allowing for the observed anti-ferromagnetic dipolar interactions between the lanthanide and the magnetic core spins. The anti-ferromagnetic coupling has also been probed and confirmed using the vibration magnetometer equipment, as reported in the literature. ${ }^{61}$

\section{Lanthanide Separation}

The magnetophoretic results revealed that the capture of the Dy ${ }^{3+}$ ions by the MagNP@DTPA nanoparticles involves a slow $\mathrm{Dy}^{3+}$ diffusion controlled adsorption kinetics, calling the attention for the time required for equilibration (>200 min) under stirring in the absence of magnetic field.

Based on the distinct affinity of DTPA for the lanthanide ions, a new method has been designed for separating the elements using magnetic nanohydrometallurgy. The principle explores the gradual enrichment of the successive fractions by the heavy elements, promoted by their favorable binding constants, which vary according to the lanthanide contraction series. After each complexation step, the particles containing the chelated ions are magnetically confined and treated with an acidic solution $(\mathrm{pH}<2)$ in order to release the lanthanides. In the case of a mixture of $\mathrm{La}^{3+}$ and $\mathrm{Nd}^{3+}$ ions, the process can be represented as:

$$
\begin{aligned}
& \text { MagNP@DTPA }(x L a, y N d)^{3+}+\mathrm{H}^{+} \rightleftharpoons \\
& \text { MagNP@DTPA }\left(\mathrm{H}^{+}\right)+\mathrm{xLa}^{3-}+\mathrm{yNd}^{3+}
\end{aligned}
$$

By starting with an equimolar mixture of $\mathrm{La}^{3+}$ and $\mathrm{Nd}^{3+}$ ions, 50:50, the first extraction process lead to enrichment of the heavy (Nd) element by 66:33. After confining and releasing the elements in acidic solutions, the simple adjustment of $\mathrm{pH}$ to 6 , is enough to promote the recapturing of the lanthanides from the enriched solution. In the second extraction, the Nd:La composition led to a 94:6 distribution, and in the third process, the $\mathrm{Nd}$ content was higher and 99\%, as illustrated in Figure 8.

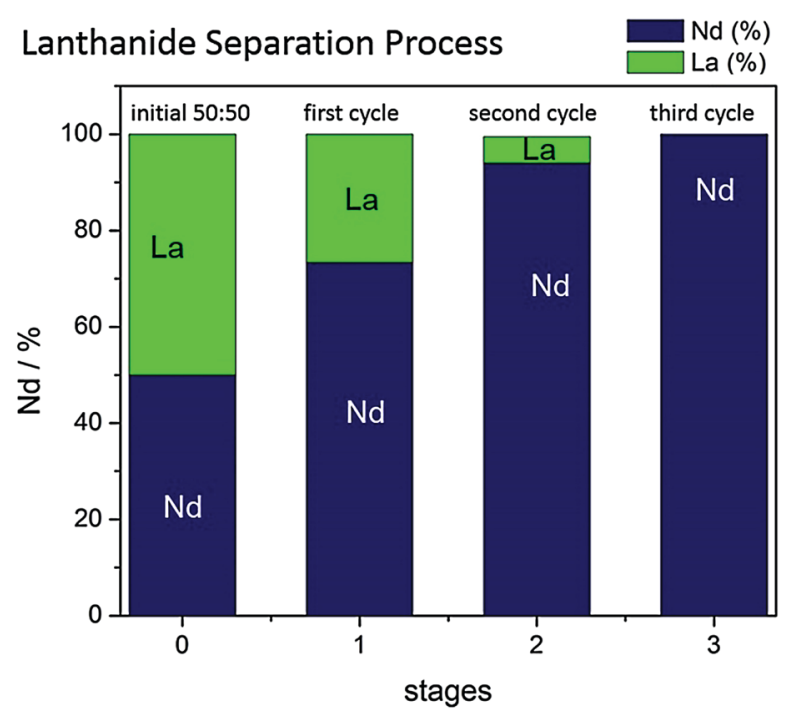

Figure 8. Fractionation of La:Nd mixtures by NHM using MagNP@DTPA, starting from an equimolar solution of the lanthanides, with an enrichment to $63: 33,94: 6$ and $100 \%$ observed in the successive cycles (reproduced with permission from reference 59).

The proposed method explores the gradual enrichment of the fractions, resembling the fractional distillation process, where each step correspond to a theoretical plates in the separation process. Our process, however, is essentially based on the affinity constants of the complexes, where the phase separation is carried out magnetically, and the elements are released by changing the $\mathrm{pH}$.

The method has proved successful even for rather similar elements, such as $\mathrm{La}^{3+}$ and $\mathrm{Nd}^{3+}$, as exemplified in Figure 8, and can be applied to ternary and even more complex mixtures, after a suitable planning.

\section{Magnetic Nanohydrometallurgy Applied to Urban Wastes and Natural Resources}

Modern technology is making extensive use of strategic elements such as copper, silver, gold, palladium and lanthanides; and the accumulation of the industrial products 
is already imposing a challenging task for the society, as exemplified by the increasing amounts of electric and electronic wastes. For this reason, the expression "urban mining" is becoming rather frequent in the literature. As a matter of fact, urban wastes can have a high content of such precious elements to be explored commercially. Several companies in the world are already exploring urban mining, showing the importance of recycling the elements for achieving sustainability. Exploration of urban mining can compete and minimize the abusive extraction of minerals from the natural resources. In this way, it can decrease the environmental problems, generally of large scale, arising from the depletion of native forests and clean water resources. In addition, it can also contribute for cleaning the urban environment from the electronic waste products and contaminants, while stimulating new jobs and technologies.

Because of its green nanotechnological characteristics, magnetic nanohydrometallurgy is particularly suitable for urban mining processes, demanding more compact reactors, low energy resources and also allowing the recycling of the superparamagnetic nanoparticles. It is efficient not only for capturing and processing the elements, but can also clean the effluents. Research from our laboratory has already demonstrated the possibility of recovering copper and silver elements from urban wastes, and for cleaning polluted effluents, particularly contaminated with mercury ions. Their good performance has also stimulated the teaching of green strategies and sustainability concepts in chemical education..$^{72}$

Copper has been initially chosen for demonstrating the NHM process in the laboratory ${ }^{28}$ since it is already produced by conventional hydrometallurgy processes, and is a strategic element in the economy, because of its involvement in construction, energy and agriculture, as well as in electric, electronic and domestic products. The element can be processed with superparamagnetic nanoparticles functionalized with diethylenediaminepropyltriethoxysilane (MagNP@EAPS) as complexing agents, as represented by:

$$
\text { MagNP@EAPS + } \mathrm{Cu}^{2+} \rightleftharpoons \text { MagNP@EAPS(Cu) }
$$

In our experiments, the initial amounts of copper in solution were in large excess in relation to the magnetic nanoparticles, and the MagNP/EAPS became saturated with copper(II) ions (encompassing about $8 \%$ from the global mass). After magnetically confining at the electrode, the metal electrodeposition was performed by applying $1.2 \mathrm{~V}$ potential. According to the observed voltammograms, the electrochemical process involved is rather fast, and all the confined metal ions can be deposited in a single step, resembling a reverse stripping analysis. After this step, the nanoparticles were released again from the electrodes, and allowed to interact with the remaining copper(II) ions in solution, in order to start another cycle. The great advantages of this process are associated with the fact that the nanoparticles are very effective carriers and good electrochemical mediators. In addition, they can be magnetically manipulated and recycled, being useful even at highly diluted solutions, where conventional hydrometallurgy is no longer feasible.

Silver is an important metal in houseware and jewelry, exhibiting the highest electrical and thermal conductivity of all elements. For this reason, it is specially used in electronics. Its high reflectivity has also been explored in mirrors. New applications are now appearing because of the recent boom of antibacterial products. ${ }^{73,74}$ For this reason, its presence as contaminant species in the environment is expected to increase, and its widespread use stimulates the interest for recovering in urban wastes. ${ }^{75}$

For the recovery of silver, an alternative low cost material for NHM, based on superparamagnetic carbon particles has been employed in our laboratory. Carbon has already been successfully employed for the adsorption of metal ions ${ }^{76}$ including gold and silver from gold-plant solutions. ${ }^{76}$ Our strategy explored the adsorption properties and the large surface area of carbon, in conjunction with the superparamagnetic properties of magnetite nanoparticles, for collecting $\mathrm{Ag}^{+}$ions from solution and to promote their rapid confinement at the working electrode surface, using an external magnet.

A typical scanning electron microscopy (SEM), image of carbon coated with magnetic nanoparticles (Cmag) can be seen in Figure 9. The material contains nanoparticles of about $7.0 \mathrm{~nm}$ dispersed all over the surface.

The initial surface area and total pore volume of Cmag obtained by $\mathrm{N}_{2}$ adsorption/desorption measurements showed a small decrease from $713 \mathrm{~m}^{2} \mathrm{~g}^{-1}$ and $0.606 \mathrm{~cm}^{3} \mathrm{~g}^{-1}$ in the original particles, to $572 \mathrm{~m}^{2} \mathrm{~g}^{-1}$ and $0.473 \mathrm{~cm}^{3} \mathrm{~g}^{-1}$, in the magnetic material, reflecting a decrease of $20 \%$ in the surface area and porosity of the carbon material.

The adsorption isotherm of silver ions onto Cmag can be better described by the Langmuir model, leading to a value of $61.5 \mathrm{mg} \mathrm{g}^{-1}$ for the adsorptive capacity at $298 \mathrm{~K}$. In comparison with the results reported for activated carbon, ${ }^{58}$ the efficiencies are rather similar, in spite of the slight reduction of the surface area by the coating of magnetic nanoparticles. However, the great advantage of Cmag is the possibility of performing efficient electrodeposition, in relation to the conventional processes, because of the preconcentration effect at the electrode, and the possibility of recycling the nanoparticles. 

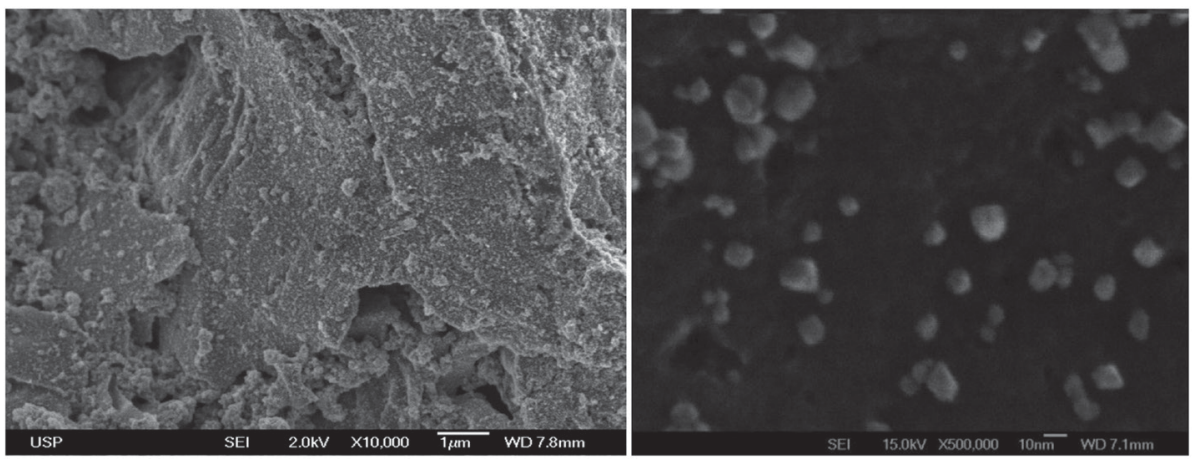

Figure 9. SEM image of carbon containing superparamagnetic nanoparticles (left), and an expanded view (right).

It has been shown that the conductivity of carbon materials depends upon the compactness of the films generated at the interface. When the carbon films are pressed, as in the case of the carbon paste electrodes, they become conducting and the electrodeposition of the adsorbed $\mathrm{Ag}^{+}$ions can occur directly over the magnetic film. In our case, however, because of the relatively small saturation magnetization value of CMag, the films collected at the electrode surface with the use of a magnet are not compact enough to exhibit intrinsic electric/electronic conductivity. Actually, they behave like a sponge, allowing the ions in equilibrium, from adsorption process, to migrate through the channel network in order to reach the electrode. As a matter of fact, ionic migration has been demonstrated by the detection of the silver deposit at the electrode surface based on EDX measurements.

As a proof of concept, an automated system was specially designed for performing successive batch cycles, encompassing the capture, transport, confinement, electrodepositon of silver, and recycling of the magnetic carbon particles from the electrode. The recovery process was successfully demonstrated by processing discarded X-ray photographic films. After a treatment of the photographic films with a nitric acid solution, the $\mathrm{pH}$ was adjusted to 5 and the solution transferred to the automated reactor, and treated with CMag under stirring. In the sequence, the external magnet was positioned at the back of the electrode and the $\mathrm{Ag}^{+} / \mathrm{CMag}$ coated electrode was submitted to $-0.5 \mathrm{~V}$, for performing the silver metal deposition. The automated process allows to operate the reactor sequentially, until the complete depletion of the silver ions from the solution.

The NHM process was also applied to the electrochemical detection and removal of mercury ions from the solution, ${ }^{33}$ using superparamagnetic nanoparticles functionalized with 3-mercaptopropyltriethoxysilane.

$$
\text { MagNP@MPTS + } \mathrm{Hg}^{2+} \rightleftharpoons \operatorname{MagNP@MPTS}\left(\mathrm{Hg}^{2+}\right)
$$

For analytical purposes this system is rather interesting, because of the high affinity of the thiol groups for the $\mathrm{Hg}^{2+}$ ions, enhancing the electrochemical signals by means of the magnetic preconcentration effects on the electrode. It can also be applied to the capture of $\mathrm{Hg}^{2+}$ ions from oil, allowing its magnetic removal and processing. Crude oil exhibits variable content of mercury ions depending on the geographic region in the world, ranging from 1 to $58,000 \mathrm{ppb} \cdot{ }^{77}$ It is a critical problem in petrochemical industries and for the environment, deserving special technologies, such as NHM, for its suitable management.

\section{Conclusions}

NHM can be feasible for the extraction, recovery and production of metallic elements, from natural sources and urban mining. By using superparamagnetic nanoparticles encompassing suitable complexing agents, the main advantage of NHM is its operation under mild, environmental conditions, at room temperature, allowing the magnetic recycling of the active agents, in an efficient and selective way. In addition, the magnetic preconcentration of the elements on the electrode surface, facilitates the electrowinning process under diluted conditions, as demonstrated for the copper and silver elements. NHM also allows to discriminate the elements by their characteristic affinities to the immobilized complexing agents, opening wide perspectives for magnetic separation in solution, as exemplified by the fractioning of the rare earth elements. Further advances in NHM will involve the development of magnetophoresis for application in analytical separations, in a similar way as it has been done in electrophoresis. Finally, NHM can be of very useful in environmental remediation, removing hazardous elements from the urban and industrial effluents, contributing for a better and sustainable world.

\section{Acknowledgments}

The support from FAPESP (2013/27425-4) and CNPq (404301/2013-8) is gratefully acknowledged. 


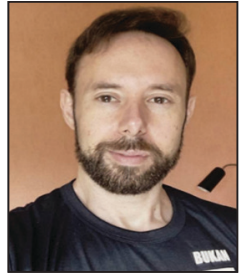

\section{Ulisses Condomitti holds} a PhD in Chemistry from the University of São Paulo. His major interests are nanotechnology, magnetoelectrochemistry and nanohydrometallurgy.

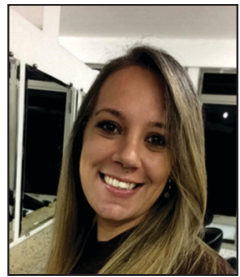

Sabrina da Nóbrega Almeida is pursuing her PhD in Chemistry at the University of São Paulo. Her major interests are nanohydrometallurgy and rare-earth recovery using superparamagnetic nanoparticles.

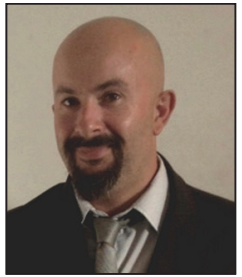

Alceu Totti Silveira Jr. holds a PhD in Chemistry from the University of São Paulo. His major interests are Green Chemistry and Nanotechnological strategies for water treatment based on magnetic nanoparticles.

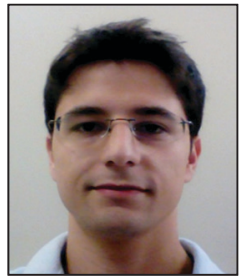

Fernando Menegatti de Melo is pursuing his PhD in Chemistry at the University of São Paulo. His major interests are on magnetic nanoparticles and quantum dots for industrial applications.

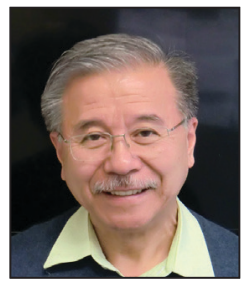

Henrique Eisi Toma holds a PhD in Chemistry and is Professor at the University of São Paulo. He is Guggenheim Fellow, Member of the Brazilian Academy of Sciences, TWAS and Grã-Cruz of the National Science Order. His major interests are Inorganic, Bioinorganic, Supramolecular Chemistry and Molecular Nanotechnology.

\section{References}

1. Hunt, A.; Matharu, A.; King, A.; Clark, J.; Green Chem. 2015 , 17, 1949.

2. Toma, H. E.; Green Chem. 2015, 17, 2027.

3. Jenck, J. F.; Agterberg, F.; Droescher, M. J.; Green Chem. 2004, $6,544$.

4. Ayres, R. U.; Resour., Conserv. Recycl. 1997, 21, 145.

5. Habashi, F.; J. Min. Metall., Sect. B 2009, 45, 1.

6. Han, K. N.; Metall. Mater. Trans. B 2003, 34, 757.

7. Rotuska, K.; Chmielewski, T.; Physicochem. Probl. Miner. Process. 2008, 42, 29.

8. Watling, H. R.; Hydrometallurgy 2013, 140, 163.
9. Watling, H. R.; Minerals 2015, 5, 1 .

10. Olson, G. J.; Brierley, J. A.; Brierley, C. L.; Appl. Microbiol. Biotechnol. 2003, 63, 249.

11. Rohwerder, T.; Gehrke, T.; Kinzler, K.; Sand, W.; Appl. Microbiol. Biotechnol. 2003, 63, 239.

12. Maley, M.; van Bronswijk, W.; Watling, H. R.; Hydrometallurgy 2009, 98, 73 .

13. Watling, H. R.; Johnson, J. J.; Shiers, D. W.; Gibson, J. A. E.; Nichols, P. D.; Franzmann, P. D.; Plumb, J. J.; Hydrometallurgy 2016, 164, 189.

14. Davenport, W. G.; King, M.; Schlessinger, M.; Biswas, A. K.; Extractive Metallurgy of Copper, $4^{\text {th }}$ ed.; Pergamon: The Netherlands, 2002.

15. Belova, V. V.; Theor. Found. Chem. Eng. 2017, 51, 599.

16. Petersen, J.; Hydrometallurgy 2016, 165, 206.

17. Ahmadi, A.; Schaffie, M.; Petersen, J.; Schippers, A.; Ranjbar, M.; Hydrometallurgy 2011, 106, 84.

18. Veit, H. M.; Bernardes, A. M.; Ferreira, J. Z.; Tenorio, J. A. S.; Malfatti, C. F.; J. Hazard. Mater. 2006, 137, 1704.

19. Scott, K.; Chen, X.; Atkinson, J. W.; Todd, M.; Armstrong, R. D.; Resour., Conserv. Recycl. 1997, 20, 43.

20. Gouvea, L. R.; Morais, C. A.; Miner. Eng. 2010, 23, 492.

21. Habashi, F.; J. Min. Metall., Sect. B 2009, 45, 1.

22. Fornari, P.; Abbruzzese, C.; Hydrometallurgy 1999, 52, 209.

23. Lemos, F. A.; Sobral, L. G. S.; Dutra, A. J. B.; Miner. Eng. 2006 , 19, 388.

24. Dutra, A. J. B.; Rocha, G. P.; Pombo, F. R.; J. Hazard. Mater. 2008, 152, 648 .

25. Panda, B.; Das, S. C.; Hydrometallurgy 2001, 59, 55.

26. Zhang, L.; Xu, Z.; J. Cleaner Prod. 2016, 127, 19.

27. Ning, C.; Lin, C. S. K.; Hui, D. C. W.; McKay, G.; Top. Curr. Chem. 2017, 375, 43.

28. Condomitti, U.; Zuin, A.; Silveira, A. T.; Araki, K.; Toma, H. E.; Hydrometallurgy 2012, 125-126, 148.

29. Araki, K.; Toma, H.; Silveira, A.; Zuin, A.; Epamino, U. C.; BR2011-5235-A2 Derwent 2014-F55013, 2013.

30. Condomitti, U.; Silveira, A. T.; Condomitti, G. W.; Toma, S. H.; Araki, K.; Toma, H. E.; Hydrometallurgy 2014, 147-148, 241.

31. Condomitti, U.; Zuin, A.; Novak, M. A.; Araki, K.; Toma, H. E.; Electrochem. Commun. 2011, 13, 72 .

32. Condomitti, U.; Zuin, A.; Silveira, A. T.; Araki, K.; Toma, H. E.; J. Electroanal. Chem. 2011, 661, 72.

33. Condomitti, U.; Zuin, A.; Silveira, A. T.; Toma, S. H.; Araki, K.; Toma, H. E.; Electroanalysis 2011, 23, 2569.

34. Edelmann, F.; Coord. Chem. Rev. 2009, 253, 2515.

35. Wang, Q.; Nono, K. N.; Syrjanpaa, M.; Charbonniere, L. J.; Hovinen, J.; Harma, H.; Inorg. Chem. 2013, 52, 8461.

36. Pihlasalo, S.; Kulmala, A.; Rozwandowicz-Jansen, A.; Hanninen, P.; Harma, H.; Anal. Chem. 2012, 84, 1386.

37. Teo, R. D.; Termini, J.; Gray, H. B.; J. Med. Chem. 2016, 59, 6012 . 
38. Shokrollahi, H.; Mater. Sci. Eng., C 2013, 33, 4485.

39. Coey, J. M. D.; IEEE Trans. Magn. 2011, 47, 4671.

40. Silva Jr., A. F.; de Campos, M. F.; Holos 2016, 32, 350.

41. Migaszewski, Z. M.; Galuszka, A.; Crit. Rev. Environ. Sci. Technol. 2015, 45, 429.

42. Gambogi, J.; Rare Earths-Mineral Commodity Summaries; USGS: USA, 2017.

43. MCTI/CNPq/CT-Mineral; Chamada 76/2013-Apoio ao Desenvolvimento Tecnológico de Terras Raras; DOU 16.09.2013.

44. de Jong, N.; Draye, M.; Favre-Reguillon A.; LeBuzit, G.; Cote, G.; Foos, J.; J. Colloid Interface Sci. 2005, 291, 303.

45. Hidayah, N. N.; Abidin, S. Z.; Miner. Eng. 2017, 112, 103.

46. Boubals, N.; Wagner, C.; Dumas, T.; Chaneac, L.; Manie, G.; Kaufholz, P.; Marie, C.; Panak, P. J.; Modolo, G.; Geist, A.; Guilbaud, P.; Inorg. Chem. 2017, 56, 7861.

47. Gras, M.; Papaiconomou, N.; Chainet, E.; Tedjar, F.; Billard, I.; Sep. Purif. Technol. 2017, 178, 169.

48. Yamin, D.; Xiangguang, G.; Yanliang, W.; Zeyuan, Z.; Chao, H.; Xiaoqi, S.; J. Rare Earths 2017, 35, 290.

49. Sun, T.; Xu, C.; Chen, J.; Duan, W.; Solvent Extr. Ion Exch. 2017, 35, 199.

50. Larsson, K.; Cullen, T. D.; Mezyk, S. P.; McDowell, R. G.; Martin, L. R.; RSC Adv. 2017, 7, 26507.

51. Mathew, D. S.; Juang, R. S.; Chem. Eng. J. 2007, 129, 51.

52. Verwey, E. J.; Overbeek, J. T. G.; The Theory of the Stability of Lyophofic Colloids; Dover: New York, 2000.

53. Toma, H. E.; Zamarion, V. M.; Toma, S. H.; Araki, K.; J. Braz. Chem. Soc. 2010, 21, 1158.

54. Stober, W.; Fink, A.; Bohn, E.; J. Colloid Interface Sci. 1968, 26,62 .

55. Svancara, I.; Vytras, K.; Kalcher, K.; Walcarius, A.; Wang, J.; Electroanalysis 2009, 21, 7.

56. Moreno-Castilla, C.; Dawidziuk, M. B.; Carrasco-Marin, F.; Morallon, E.; Carbon 2012, 50, 3324.

57. Davidson, R. J.; Veronese, V.; Nkosi, M. V.; J. South. Afr. Inst. Min. Metall. 1979, 79, 281.

58. Omri, A.; Benzina, M.; Desalin. Water Treat. 2013, 51, 2317. 59. Almeida, S. N.; Toma, H. E.; Hydrometallurgy 2016, 161, 22.

60. Limousin, G.; Gaudet, J. P.; Charlet, L.; Szenknect, S.; Barthès, V.; Krimissa, M.; Appl. Geochem. 2007, 22, 249.
61. de Melo, F. M.; Almeida, N.; Uezu, N. S.; Alberto, C.; Ramirez, O.; Domingues, A.; Toma, H. E.; J. Nanosci. Nanotechnol. 2018, 18,4155 .

62. Toma, H.; Química de Coordenação, Organometálica e Catálise, $2^{\mathrm{a}}$ ed.; Blucher: São Paulo, 2016.

63. de Melo, F. M.; Almeida, N.; Domingues, A.; Toma, H. E.; NanoWorld J. 2017, 3, 38.

64. Leong, S. S.; Ahmad, Z.; Lim, J.; Soft Matter 2015, 11, 6968.

65. Benelmekki, M.; Martinez, L. M.; Andreu, J. S.; Camacho, J.; Faraudo, J.; Soft Matter 2012, 8, 6039.

66. Andreu, J. S.; Camacho, J.; Faraudo, J.; Benelmekki, M.; Rebollo, C.; Martínez, L. M.; Phys. Rev. E 2011, 84, 1.

67. Faraudo, J.; Andreu, J. S.; Camacho, J.; Soft Matter 2013, 9 , 6654.

68. Friedman, G.; Yellen, B.; Curr. Opin. Colloid Interface Sci. 2005, 10, 158.

69. Lim, J.; Lanni, C.; Evarts, E. R.; Lanni, F.; Tilton, R. D.; Majetich, S. A.; ACS Nano 2011, 5, 217.

70. Andreu, J. S.; Barbero, P.; Camacho, J.; Faraudo, J.; J. Nanomater. 2012, 678581.

71. Schaller, V.; Kraling, U.; Rusu, C.; Petersson, K.; Wipenmyr, J.; Krozer, A.; Wahnstrom, G.; Sanz-Velasco, A.; Enoksson, P.; Johansson, C.; Kräling, U.; Wahnström, G.; J. Appl. Phys. 2008, 104, 93918.

72. da Silva, D. G.; de Melo, F. M.; Silveira Jr., A. T.; da Cruz, B. C.; Pestana Prado, C. C.; de Vasconcelos, L. C.; Sanches Lucas, V. A.; Toma, H. E.; J. Chem. Educ. 2016, 93, 1929.

73. Levard, C.; Hotze, E. M.; Lowry, G. V.; Brown Jr., G. E.; Environ. Sci. Technol. 2012, 46, 6900.

74. Sen, I. K.; Mandal, A. K.; Chakraborti, S.; Dey, B.; Chakraborty, R.; Islam, S. S.; Int. J. Biol. Macromol. 2013, 62, 439.

75. Ratte, H. T.; Environ. Toxicol. Chem. 1999, 18, 89.

76. Dias, J. M.; Alvim-Ferraz, M. C. M.; Almeida, M. F.; RiveraUtrilla, J.; Sanchez-Polo, M.; J. Environ. Manage. 2007, 85, 833.

77. Wilhelm, S. M.; Mercury Technology Services; US Environment Protection Agency: Washington, DC, 20460, 2001.

Submitted: October 10, 2017

Published online: January 22, 2018 